\title{
“Clinical Masks" of Congenital Malformations of Urinary System in Children of Early Age
}

\author{
Nataliia S. Lukyanenko a, Danara M. Imanmadiyeva ${ }^{b}$, Vilena T. Dolinnaya ${ }^{c}$, Anastasiya Spaska ${ }^{d}$
}

Manuscript submitted: 27 May 2021, Manuscript revised: 18 August 2021, Accepted for publication: 3 September 2021

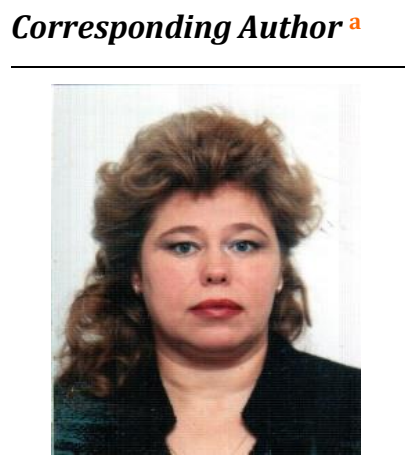

Keywords

diagnostic algorithm; pyelonephritis symptoms; hospitalization; medical effects; nephropathy; pressing health; young patients;

\begin{abstract}
Nowadays there is an increase in nephropathy in young children, which is associated not only with environmental impacts, but also with an increase in the incidence of congenital and hereditary caused forms of diseases, an increase in the incidence of mothers, and an improvement in diagnosis. In order to analyze the frequency of congenital malformations of the urinary system in young children under the "clinical masks" of various somatic pathologies, 864 cards of inpatients that were treated in the Early Childhood Department of the Regional Children's Clinical Hospital "OKHMATDYT" during 2013 were analyzed. The authors came to the conclusion that congenital malformations of the urinary system in young children are a frequent pathology, diagnosed in $44.6 \%$ of children admitted to the To the Department of the early age for acute pyelonephritis to get $10.3 \%$ of all children who were admitted to hospital treatment. The introduction of a two-stage algorithm for the diagnosis of congenital malformations of the urinary system allows us to recognize their various "clinical masks" and timely establish a clinical diagnosis of anomalies. This approach makes it possible to conduct adequate therapy and reduce high rates of childhood morbidity and disability, and has significant medical and social effects.
\end{abstract}

International Journal of Health Sciences (C) 2021. This is an open access article under the CC BY-NC-ND license (https://creativecommons.org/licenses/by-nc-nd/4.0/).

\section{Contents}

Abstract.

a Institute of Hereditary Pathology of the National Academy of Medical Sciences of Ukraine, Lviv, Ukraine | Danylo Halytsky Lviv National Medical University, Lviv, Ukraine

b Semey Medical University, Semey, Republic of Kazakhstan

c Semey Medical University, Semey, Republic of Kazakhstan

d Ajman University, College of Medicine, Al-Jurf, Ajman, United Arab Emirates | Center of Medical and Bio-allied Health Sciences Research, Ajman University, Al-Jurf, Ajman, United Arab Emirates 


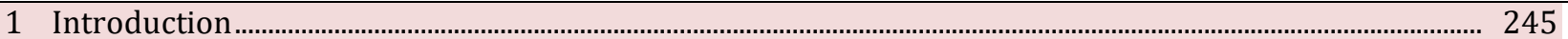

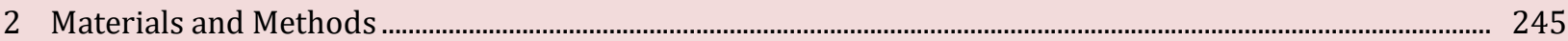

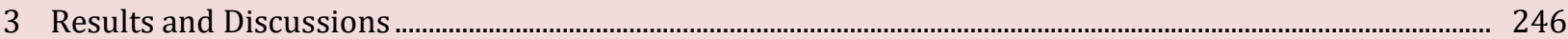

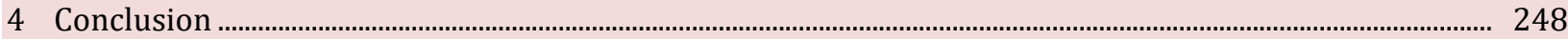

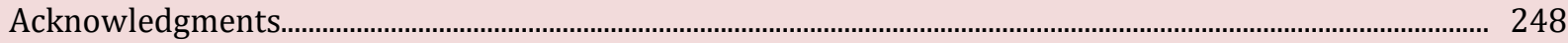

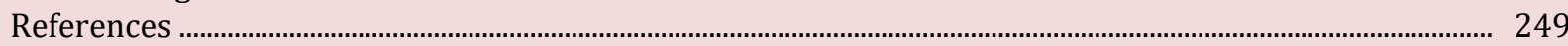

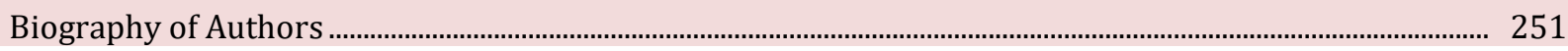

\section{Introduction}

Diseases of the urinary system (DUS) are not only widespread, but also tend to increase, and to a greater extent, among young children (Veltischev, 2000; Geldt, 2002). Today, in pediatric nephrology, a separate direction is clearly distinguished - nephrology of early childhood or nephrology (Papayan \& Styazhkina, 2002; Horalskyi et al., 2020). In modern literature, there are more and more reports on the pathology of the urinary system in young children. The increase in nephropathy in young children is associated not only with environmental impacts, but also with an increase in the incidence of congenital and hereditary caused forms of diseases, an increase in the incidence of mothers, and an improvement in diagnosis. Recent epidemiological studies indicate that the frequency of diseases of the urinary system varies between 0.4 to $5.4 \%$, and in young children it is higher and amounts to $11 \%$ (Pereverzev, 2000). In patients of this age group, as a rule, there are no symptoms characteristic of the pathology of the urinary system in older children, which complicates the diagnosis and leads to a late diagnosis and, accordingly, untimely treatment. Verification of the diagnosis is further complicated by the fact that diseases of the urinary system in young children often pass under the clinical masks of other diseases, and only examination aimed at this pathology allows timely and correct diagnosis (Corbett \& McAndrew, 2018; Ortega-Abente \& Ruiz-Flores, 2021).

Some newborns develop jaundice, which may be one of the main symptoms of pyelonephritis. Jaundice in these cases is accompanied by an increase in the blood of free and bound bilirubin, an increase in the liver and spleen, the appearance of dark urine, sometimes a slightly stained stool. Urinary tract infections in infants and young children are most often manifested as secondary pyelonephritis(Nelson et al., 2019; Janjua et al., 2019; Tezol et al., 2018; Chala et al., 2021; Sapko, 2020). It arises as a result of microbial invasion with obstructive uropathy, or as a result of the involvement of the renal parenchyma in the infectious process during sepsis. In the vast majority of newborns and young children with an infection of the urinary system, vesicoureteral or vesicoureteral reflux, hydronephrosis, ureterocele, and obstruction of the pelvic-ureteric eye are found. Urinary syndrome develops against a background of low-grade fever, an increase in symptoms of intoxication, increased neurological symptoms, tissue pastes, and the appearance of pathological impurities in the feces (Papayan \& Styazhkina, 2002; Buettcher et al., 2021; Iacobelli, Bonsante \& Guignard, 2009).

Thus, improving nephrological care for young children remains one of the pressing health problems. Diseases of the urinary system are characterized by a significant prevalence in early childhood, the tendency of the pathological process to a protracted and recurrent course, the absence of a specific clinical picture, and the ability of diseases of the urinary system to go under the "clinical masks" of other diseases, the development of complications leading to disability of the patient. All this determines the early diagnosis of diseases of the urinary system and, in particular, congenital malformations of the urinary system, as the main reason for the development of pyelonephritis and subsequent disability of young children.

\section{Materials and Methods}

In 2013, in the early childhood department of the "OKHMATDYT" L'viv Regional Children's Clinical Hospital, we introduced the algorithm we developed to diagnose congenital malformations of the urinary system with the aim of timely verification and adequate treatment. We were interested in analyzing the frequency of congenital malformations of the urinary system when they were searched for among young children who came to the regional hospital during 2013 with various pathologies. Objective: to analyze the frequency of

Lukyanenko, N. S., Imanmadiyeva, D. M., Dolinnaya, V. T., \& Spaska, A. (2021). “Clinical masks” of congenital malformations of urinary system in children of early age. International Journal of Health Sciences, 5(3), 244-251. https://doi.org/10.53730/ijhs.v5n3.1458 
congenital malformations of the urinary system in young children with various pathologies, according to the regional hospital in 2013 (Farkash et al., 2012; Gamé et al., 2008).

Material and scope of the study: cards of an inpatient patient of 864 young children (1 month - 3 years) with a variety of pathologies, which were received for inpatient treatment in the early childhood department of the "OKHMATDYT" Regional Children's Clinical Hospital during 2013. In this study, the following research methods were used: general clinical, genealogical, ultrasonic, biochemical, radiological, medical-statistical analysis. In the process of research by using methods of analysis and synthesis of information, it was determined that diseases of the urinary system are characterized by a significant prevalence in early childhood, the predisposition of the pathological process to a prolonged and recurrent course. It was also determined that diseases of the urinary system are characterized by the absence of a specific clinical picture and the ability of diseases of the urinary system to pass under the "clinical masks" of other diseases. Through the study of literature sources, as well as our own research, it was determined that this leads to disability of the patient (Yiee et al., 2007; Valent et al., 2019).

The results of the study and the use of the method of identification and synthesis of information, allowed us to draw conclusions. It was concluded that the introduction of a two-stage algorithm for the diagnosis of congenital malformations of the urinary system allows to recognize their various "clinical masks" and diagnose disorders of the urinary system in a large number of young children. The general conclusions indicate that this allows for adequate therapy and reduces high rates of childhood morbidity and disability, as well as has a significant medical and social effect. As a result of the literature analysis, the following conclusions were made: the kidneys and urinary tract are a common source of infection in children of all ages, especially infants and young children, the younger the child, the more atypical the symptoms. Urinary tract infections (UTI) are often associated with functional or malignant uropathy, such as vesicoureteral reflux or obstruction (Renda, 2017).

\section{Results and Discussion}

Unlike older children, a disease of the urinary system is more common in newborn boys than in girls. According to Papayan \& Is (2002), this pathology is 5 times more common in boys than in girls. This is due to more frequent malformations of the urinary system. At the same time, boys are more likely than boys to have bacteremia. Most children have a low-symptom course of the disease, probably related to the peculiarities of the immunological response, but a vivid picture of general intoxication can also be noted. Symptoms of diseases of the urinary system in infants are nonspecific - there are no dysuria phenomena and urinary syndrome, there is no anxiety during urination, an increase in its frequency or anuria. All this leads to delay hospitalization of children and, accordingly, late diagnosis. Symptoms of pyelonephritis in these cases are generally infectious - weakness in sucking or a rapid decrease in appetite before anorexia, insufficient increase, stabilization, or decrease in body weight with the subsequent development of symptoms of dehydration. Often there is general anxiety of the child, increased irritability to convulsions or, conversely, lethargy, drowsiness. In many children, the disease begins with frequent vomiting and regurgitation or dyspeptic disorders. Sick children are lethargic, hypotonic, with a pale gray skin color (Charnaya \& Ahn, 2019; Diong et al., 2019; Wachnicka-Bąk et al., 2020).

The basis for successful treatment of the pathology of the urinary system and the prevention of complications of the disease is its earliest diagnosis. So, for the purpose of early diagnosis of the pathology of the urinary system, we introduced an algorithm for a two-stage diagnosis of congenital malformations of the urinary system in young children, regardless of the underlying pathology for which the child was hospitalized, which includes at the first stage:

1) A thorough history taking, including with a focus on the genealogical history and the presence of pathology of the urinary system in the family and during pregnancy in the mother.

2) Compulsory study of the general analysis of urine and the results of biochemical blood tests for the content of urea and creatinine for all children.

3) Obligatory ultrasound of the kidneys for all children, as a screening method to suspect the presence of a congenital malformation of the urinary system and the inflammatory process of the kidneys. 
4) At the second stage, with a high probability of a child having pathology of the urinary system or a family history of nephropathy, it is mandatory.

5) Conducting routine clinical studies (urine culture on the flora and the degree of bacteriuria, urinalysis, determination of the rhythm of spontaneous urination, blood pressure measurement).

6) Obligatory conduction of cystography by my own perfected and adapted to young children technique in connection with the high probability of detecting vesicoureteral reflux, neurogenic bladder dysfunction and infravesical obstruction in young children.

7) According to indications, carrying out infusion excretory urography in a group of children with suspected anatomical defects of the kidneys.

8) Tests for proteinuria, aminoaciduria, calciumuria and glucosuria to clarify the tubular functions of the kidneys and determine the content of creatinine and glycosaminoglycan's in the urine, as indicators of the functional state of glomeruli.

9) Consultation of a pediatric nephrologist and urologist.

Thanks to the introduction of such a two-stage algorithm for the diagnosis of congenital malformations of the urinary system, this diagnosis was verified in 89 children, which accounted for $10.3 \%$ of all children admitted to inpatient treatment during 2013. With a preliminary diagnosis of pyelonephritis, in 2013, 115 children were admitted to the department, 51 of them had one or another congenital pathology of the urinary system $(44.6 \%)$, which coincides with the data of various authors that pyelonephritis in early children age usually occurs against a background of congenital pathology of the urinary system [2;3]. Among 38 children with congenital malformations of the urinary system, two (5.3\%) received a preliminary diagnosis of epileptic syndrome, six (15.8\%) with hypotrophy of unspecified origin, 8 children $(21.1 \%)$ with staphylococcal disease, eight $(21.1 \%)$ - with sepsis and septicopyemia, 9 (23.6\%) - with pneumonia, $5(13,1 \%)$ - with acute bronchitis. Among all the children who were diagnosed with congenital malformations of the urinary system, 33 children (37.1\%), infravesical obstruction - 17 children (19.1\%), kidney doubling - 11 children (12.4\%), renal hydronephrotic transformation - 10 children (11.2\%), kidney rotation and nephroptosis - 4 children (4.4\%), kidney hypoplasia - 3 children (3.4\%), two or one-sided pyeloectasia -2 children $(2.2 \%)$, in addition, 29 children (32.6\%) were diagnosed with neurogenic bladder dysfunction (Teng et al., 2007; Fine et al., 1990).

The kidneys and urinary tract are a common source of infection in children of all ages, especially infants and young children. The main risk factors for complications after urinary tract infections are congenital renal and urinary tract disorders and bladder dysfunction. Urinary tract infections (UTIs) should be considered in any child with an unresolved fever. The difference between the upper and lower UTI is crucial for proper management (Kusumajaya, 2021; Lim et al., 2021). The method of urine collection should be based on age and risk factors. Diagnosis of UTI requires urine analysis and significant growth of the pathogen in culture. Treatment of UTI should be based on practical considerations of age and clinical manifestations with adjustment of initial antimicrobial therapy according to the antimicrobial susceptibility test. All children, regardless of age, should undergo urinary tract ultrasound after pyelonephritis. Antibiotic prophylaxis is generally not recommended. The author's note that based on the latest data and in accordance with international guidelines, members of the Swiss Society of Pediatric Infectious Diseases, nephrologists and urologists have developed multidisciplinary Swiss consensus guidelines that provide clinicians with clear guidelines for diagnosis. Type and duration of treatment, antimicrobial treatment options, indications for imaging and antibiotic prophylaxis (Buettcher et al., 2021).

The authors of study «Urinary tract infections in children» note that urinary tract infections (UTIs) are relatively common in children. The younger the child, the more atypical the symptoms. UTI is often associated with functional or malignant uropathy, such as vesicoureteral reflux or obstruction. Each infected child should undergo appropriate imaging studies. The prognosis of uncomplicated UTI is very good, but less favorable if the UTI is associated with urological abnormalities. The authors note that the development of pyelonephritis scars can lead to the formation of scars on the kidneys, which may be associated with intrarenal reflux. Shortterm treatment for uncomplicated UTI is recommended. Complicated UTI with frequent recurrences requires preventive chemotherapy. Such treatment should also be considered when UTI is associated with vesicoureteral reflux. Surgery may be prescribed in case of severe urological malformations. Medical or surgical treatment of UTI should be accompanied by urine culture when the child has a fever. Antibiotic treatment of acute pyelonephritis should be started immediately, preferably intravenously. The transition to

Lukyanenko, N. S., Imanmadiyeva, D. M., Dolinnaya, V. T., \& Spaska, A. (2021). “Clinical masks" of congenital malformations of urinary system in children of early age. International Journal of Health Sciences, 5(3), 244-251. https://doi.org/10.53730/ijhs.v5n3.1458 
oral therapy can occur after receiving the results of antibiotics. In conclusion, the authors note that UTIs pose a serious risk to newborns; it is desirable to observe them in specialized centers. The transition to oral therapy can occur after receiving the results of antibiotics (Iacobelli et al., 2009; Widana et al., 2021).

Diong et al. (2019), in their study notes that parents' knowledge of nephrotic syndrome and recurrence of the disease is important for early detection and treatment of recurrence to avoid complications. According to published studies, parents' knowledge of nephrotic syndrome is insufficient. The authors note that to date in Malaysia there are no studies on parental awareness of childhood nephrotic syndrome. The aim of the study was to determine the level of knowledge about the urgency and recurrence of the disease in parents of children with nephrotic syndrome and to identify factors influencing knowledge about nephrotic syndrome and relapse (Cigarroa et al., 1989; Kikkawa et al., 2003).

\section{Conclusion}

Diseases of the urinary system are characterized by a significant prevalence in early childhood, the tendency of the pathological process to a protracted and recurrent course, the absence of a specific clinical picture, and the ability of diseases of the urinary system to go under the "clinical masks" of other diseases, the development of complications leading to disability of the patient. All this determines the early diagnosis of diseases of the urinary system and, in particular, congenital malformations of the urinary system, as the main reason for the development of pyelonephritis and subsequent disability of young children. The introduction of a two-stage algorithm for the diagnosis of congenital malformations of the urinary system makes it possible to recognize their various "clinical masks" and diagnose urinary system abnormalities in a significant number of young children. This makes it possible to conduct adequate therapy and reduce high rates of childhood morbidity and disability, and has a significant medical and social effect (Cohen et al., 1996; Choudhury \& Marsh, 1999).

\section{Acknowledgments}

We are grateful to two anonymous reviewers for their valuable comments on the earlier version of this paper. 


\section{References}

Buettcher, M., Trueck, J., Niederer-Loher, A., Heininger, U., Agyeman, P., Asner, S., ... \& Neuhaus, T. J. (2021). Swiss consensus recommendations on urinary tract infections in children. European journal of pediatrics, 180(3), 663-674.

Chala, I., Feshchenko, D., Dubova, O., Zghozinska, O., Solodka, L., \& Sokulskyi, I. (2021). Blood lipid profile as a diagnostic marker of acute pancreatitis in dogs. Scientific Horizons, 24(1), 14-21.

Charnaya, O., \& Ahn, S. Y. (2019). Quality Improvement Initiative to Reduce Admissions for Nephrotic Syndrome Relapse in Pediatric Patients. Frontiers in pediatrics, 7, 112.

Choudhury, L., \& Marsh, J. D. (1999). Myocardial infarction in young patients. The American journal of medicine, 107(3), 254-261. https://doi.org/10.1016/S0002-9343(99)00218-1

Cigarroa, R. G., Lange, R. A., Williams, R. H., \& Hillis, D. (1989). Dosing of contrast material to prevent contrast nephropathy in patients with renal disease. The American journal of medicine, 86(6), 649-652. https://doi.org/10.1016/0002-9343(89)90437-3

Cohen, S. Y., Laroche, A., Leguen, Y., Soubrane, G., \& Coscas, G. J. (1996). Etiology of choroidal neovascularization in young patients. Ophthalmology, 103(8), 1241-1244. https://doi.org/10.1016/S01616420(96)30515-0

Corbett, H. J., \& McAndrew, H. F. (2018). Indications for Investigation of the Urinary Tract in the Newborn. In Rickham's Neonatal Surgery (pp. 1161-1170). Springer, London.

Diong, S. C. (2019). Parental knowledge on nephrotic syndrome and disease relapse in children. Med J Malaysia, 74(4), 289.

Farkash, E., Weintraub, A. Y., Sergienko, R., Wiznitzer, A., Zlotnik, A., \& Sheiner, E. (2012). Acute antepartum pyelonephritis in pregnancy: a critical analysis of risk factors and outcomes. European Journal of Obstetrics \& Gynecology and Reproductive Biology, 162(1), 24-27. https://doi.org/10.1016/j.ejogrb.2012.01.024

Fine, M. J., Smith, D. N., \& Singer, D. E. (1990). Hospitalization decision in patients with community-acquired pneumonia: a prospective cohort study. The American journal of medicine,89(6), 713-721. https://doi.org/10.1016/0002-9343(90)90211-U

Gamé, X., Castel-Lacanal, E., Bentaleb, Y., Thiry-Escudié, I., De Boissezon, X., Malavaud, B., ... \& Rischmann, P. (2008). Botulinum toxin A detrusor injections in patients with neurogenic detrusor overactivity significantly decrease the incidence of symptomatic urinary tract infections. European urology, 53(3), 613619. https://doi.org/10.1016/j.eururo.2007.08.039

Geldt, V. G. (2002). Bladder dysfunction in young children. Pediatrics, 5, 80-87.

Horalskyi, L., Kovalchuk, O., \& Sokulskyi I. (2020). Pathamorphological changes of cats pancreata under acute pancreatitis. Scientific Horizons, 8(93), 149-157.

Iacobelli, S., Bonsante, F., \& Guignard, J. P. (2009). Urinary tract infections in children. Archives de pediatrie: organe officiel de la Societe francaise de pediatrie, 16(7), 1073-1079.

Janjua, H. S., Lam, S. K., Gupta, V., \& Krishna, S. (2019). Congenital Anomalies of the kidneys, collecting system, bladder, and urethra. Pediatrics in review, 40(12), 619-624.

Kikkawa, R., Koya, D., \& Haneda, M. (2003). Progression of diabetic nephropathy. American journal of kidney diseases, 41(3), S19-S21. https://doi.org/10.1053/ajkd.2003.50077.

Kusumajaya, A. A. N. (2021). Individual and social environmental factor as risk factor of BMI-for-age in school children. International Journal of Health Sciences, 5(2), 89-98.

Lim, H., Sukmawati, M., Artana, W. D., Kardana, M., \& Putra, P. J. (2021). Validity of neutrophil lymphocyte count ratio in neonatal sepsis. International Journal of Health Sciences, 5(2), 53-61.

Nelson, C. P., Lee, R. S., Trout, A. T., Servaes, S., Kraft, K. H., Barnewolt, C. E., ... \& Chow, J. S. (2019). Interobserver and intra-observer reliability of the urinary tract dilation classification system in neonates: a multicenter study. The Journal of urology, 201(6), 1186-1192.

Oral, O., Toprak, M.H.H., Uysal, F., Bostan, O.M. \& Cil, E. (2019). The frequency of asymptomatic urinary system abnormalities in children detected with cineurography imaging during angiocardiography. Cardiology in the Young, 29(2), 119-122.

Ortega-Abente, L., \& Ruiz-Flores, J. (2021). Psychological aspects as the components of academic mobility of medical workers. Scientific Bulletin of Mukachevo State University. Series "Pedagogy and Psychology", $7(2), 54-62$.

Lukyanenko, N. S., Imanmadiyeva, D. M., Dolinnaya, V. T., \& Spaska, A. (2021). "Clinical masks" of congenital malformations of urinary system in children of early age. International Journal of Health Sciences, 5(3), 244-251. 
Papayan, A. V., \& IS, S. (2002). Neonatal, naya nefrologia: rucovodstvo [Neonatal nephrology, textbook]. Saint Petersburg, Piter Publ.

Papayan, A. V., \& Styazhkina, I. S. (2002). Neonatalnaya nefrologiya: Rukovodstvo. SPb, 84(123), 448.

Pereverzev, A.S. (2000). Obstructive uronephropathy in children. In Proceedings of the VIII International Congress of Urology "Actual Problems of Pediatric Urology", (pp. 3-28).

Renda, R. (2017). Renal outcome of congenital anomalies of the kidney and urinary tract system: a singlecenter retrospective study. Minerva urologica e nefrologica= The Italian journal of urology and nephrology, 70(2), 218-225..

Sapko, S. A. (2020). Peculiarities of influence of the preparation moxistop (tablet) on biochemical indicators of blood of small pets. Scientific Messenger of LNU of Veterinary Medicine and Biotechnologies. Series: Veterinary Sciences, 22(100), 78-83.

Teng, C. I., Ing, C. K., Chang, H. Y., \& Chung, K. P. (2007). Development of service quality scale for surgical hospitalization. Journal of the Formosan Medical Association, 106(6), 475-484. https://doi.org/10.1016/S0929-6646(09)60297-7

Tezol, Ö., Makharoblidze, K., Hallığlu, O., Delibaş, A., \& Türkegün, M. (2018). Bayley-III Scores of Children with Congenital Anomalies of the Kidney and Urinary Tract. Erciyes Medical Journal/Erciyes Tip Dergisi, 40(3).

Valent, P., Akin, C., Bonadonna, P., Hartmann, K., Brockow, K., Niedoszytko, M., ... \& Metcalfe, D. D. (2019). Proposed diagnostic algorithm for patients with suspected mast cell activation syndrome. The Journal of Allergy and Clinical Immunology: In Practice, 7(4), 1125-1133. https://doi.org/10.1016/j.jaip.2019.01.006

Veltischev, Yu. (2000). Problems of child health protection in Russia. Questions of Perinatology and Pediatrics, 1, 5-9.

Wachnicka-Bąk, A., Będzichowska, A., Jobs, K., \& Kalicki, B. (2020). Analysis of the course of urinary tract infections in children up to 24 months of age - 7-year follow-up of one center.

Widana, I.K., Sumetri, N.W., Sutapa, I.K., Suryasa, W. (2021). Anthropometric measures for better cardiovascular and musculoskeletal health. Computer Applications in Engineering Education, 29(3), 550561. https://doi.org/10.1002/cae.22202

Yiee, J. H., Garcia, N., Baker, L. A., Barber, R., Snodgrass, W. T., \& Wilcox, D. T. (2007). A diagnostic algorithm for urachal anomalies. Journal of pediatric urology, 3(6), 500-504. https://doi.org/10.1016/j.jpurol.2007.07.010 


\section{Biography of Authors}

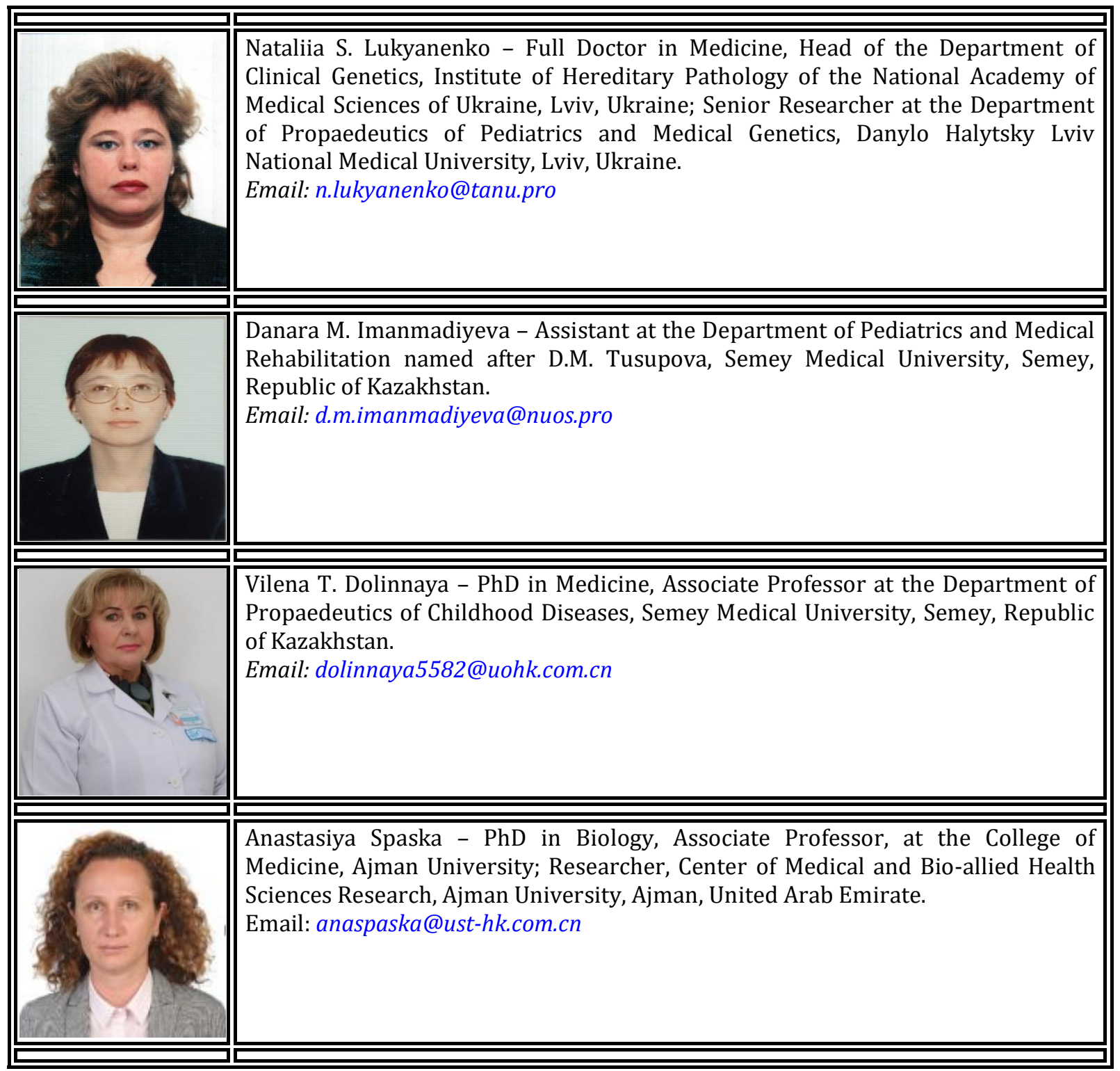

Lukyanenko, N. S., Imanmadiyeva, D. M., Dolinnaya, V. T., \& Spaska, A. (2021). "Clinical masks" of congenital malformations of urinary system in children of early age. International Journal of Health Sciences, 5(3), 244-251. https://doi.org/10.53730/ijhs.v5n3.1458 